\title{
Chemical Kinetics for Synthesis of Triacetin from Biodiesel Byproduct
}

\author{
Zahrul Mufrodi \\ Department of Chemical Engineering, Ahmad Dahlan University \\ 9 Kapas Street, Yogyakarta 55166, Indonesia \\ Tel: 62-274-743-6596_E-mail: zahrul_mufrodi@yahoo.com.sg \\ Sutijan, Rochmadi \& Arief Budiman \\ Department of Chemical Engineering, Gadjah Mada University \\ 2 Grafika Street, Yogyakarta 55281, Indonesia
}

Received: December 9, 2011

Accepted: January 29, 2012 Published: April 1, 2012

doi:10.5539/ijc.v4n2p101

URL: http://dx.doi.org/10.5539/ijc.v4n2p101

The research is financed by KKP3T department of agriculture and Department of national education Indonesia

\begin{abstract}
The reaction kinetic of the glycerol acetylation with acetic acid catalyzed by sulfuric acid has been studied in the frame of continuous triacetin production. Glycerol, acetic acid and sulfuric acid catalyst were reacted in a batch reactor, in order to get reaction kinetics data. The mole ratio of catalyst to glycerol and temperature were studied during the experience. This study concluded that the selectivity of triacetin increased with increase in mole ratio of catalyst to glycerol. Increasing temperatures lead to increase selectivity of triacetin. It will decreased at the time of acetic acid has begun to evaporate. Triacetin synthesis is an exothermic reaction, a higher reaction temperature will cause in shifting the balance toward formation of reactants. This needs to be anticipated by taking one of the products so that the equilibrium shifting toward product formation.
\end{abstract}

Keywords: Reaction kinetic, Glycerol, Acetylation, Triacetin, Acetic acid

\section{Introduction}

Needs of oil energy sources from fossil fuels are increasing, while inventories are running low. The development of alternative fuels from renewable natural resources becomes one option that is expected to overcome this situation. Alternative fuels recently widely used are biodiesel. Glycerol is a byproduct of biodiesel production. Variety of value added special and fine chemicals as pharmaceutical, personal care, polyether, triacetin, alkyd resins, as emulsifier, softener agent, stabilizer, wetting agent for bakery products, ice creams, tobacco, lotions and other countless pharmaceutical and cosmetic applications can be produced from glycerol (Bonet et al., 2009; Galan et al., 2009). Glycerol acetylation is one of the alternative utilization of glycerol. This synthesis produces triacetin that has applications as fuel additives (Reddy et al., 2010).

Synthesis of triacetin from glycerol and acetic anhydride has been studied since 1963 (trevoy \& Tegg, 1963). There are several studies about catalysts for the reaction of glycerol and acetic acid. Synthesis of triacetin from glycerol and acetic acid needed 72 hours in the presence of homogenous catalyst (Lu \& Ma, 1991). Solid catalyst such as aminosulphonate (Hou et al., 1998), phosphotungstic, mesoporous silica with sulfonic acid groups (Zang \& Yuan, 2001), p-toluensulfone (Liu et al., 2007), Amberlyst-15 or SAC-13 (Nafion-SiO 2 ) Melero et al., 2007) and $\mathrm{SO}_{4}{ }^{2-} / \mathrm{ZrO}_{2}-\mathrm{TiO}_{2}$ (Wu et al., 2007). Another to reduce reaction time. Acetylation of glycerol with acetic acid has been carried out in the presence of zeolites and ionic resin. Another experiment used a catalyst Amberlist-15, K-10, Niobic acid, HZMS-5 and HUSY (Goncalves et al., 2008). However these efforts have not obtained expected results.

Synthesis of triacetin using solid and liquid catalyst with the process modification was developed to get a shorter reaction time. Several experiments were done, for example an experiment through two steps. The first step used 
Amberlyst-35 catalyst at $105{ }^{\circ} \mathrm{C}$ and run for 4 hours. The second step was the addition of acetic anhydride. After reacted for 15 minutes, triacetin selectivity is $100 \%$ (Liao et al., 2009). The synthesis of triacetin was done using fixed bed reactor at a temperature of $50{ }^{\circ} \mathrm{C}$ with amberlyst catalyst. The best result was obtained on ratio of acetic acid to glycerol was 3:1 (Fukumura et al., 2009). These last 2 years studies were done by using different catalysts and operating conditions were modified to get the results and reaction time that relatively equal (Balaraju et al., 2010; Liao et al., 2010; Silva et al., 2010, Khayoon et al., 2011; Ferreira et al., 2011). All of the above studies did not explain the kinetics for synthesis triacetin.

Synthesis of triacetin without catalyst has performed in a stirred reactor at a pressure of $1070 \mathrm{kPa}, 290 \mathrm{rpm}$ of stirrer speed, temperatures of 120 and $160{ }^{\circ} \mathrm{C}$ and resulting in selectivity of triacetin was $54 \%$. Reaction kinetics without the catalyst was reviewed (Ferreira et al., 2009). In this paper the reaction kinetic of the glycerol acetylation with acetic acid catalyzed by sulfuric acid has been studied in the frame of continuous triacetin production.

\section{Materials and Methods}

\subsection{Reagents}

Triacetin is made of $93 \%$ glycerol (production of P \& G Chemicals) and $98 \%$ acetic acid (production of Petrochemical Chang Cun) using sulfuric acid as catalyst (Merck Index No. 016-020-00-8).

\subsection{Experimental Methods}

The reaction occurred in a three-neck flask equipped with heating mantle, cooling system, mercury stirrer, thermometer and sampling equipment. Reaction was carried out with variable of mole ratio of catalyst to glycerol and temperature. Samples were taken every 15 minutes and were analyzed using gas chromatography (GC) and GCMS, The mixture of compounds that contain glycerol, acetic acid, monoacetin, diacetin and triacetin can be separated and analyze easily (Morrissette \& Link, 1964).

\subsection{Analysis Instrument}

The instrumentation that used was gas chromatography GC Agilent 6890N MSD 5975B, HP-5ms column $5 \%$ Phenyl methyl siloxane, Model Number: Agilent 19091S-433, the injector temperature $275{ }^{\circ} \mathrm{C}$, the temperature at the detector: MS Quad $150{ }^{\circ} \mathrm{C}$, injection volume of 1 micro liter, injector pressure of $3.27 \mathrm{psi}$. The data obtained was processed to obtain the reaction rate equation.

\section{Theory/calculation}

The reaction of glycerol and acetic acid is a parallel series reactions that sequentially produce monoacetin, diacetin and triacetin (Figure 1). The reacting system is reduced to three equations main equilibrium reactions as follows.

$$
\begin{gathered}
-\mathrm{r}_{\mathrm{G}}=-\mathrm{k}_{1} \mathrm{C}_{\mathrm{G}} \cdot \mathrm{C}_{\mathrm{AA}}+\mathrm{k}_{2} \mathrm{C}_{\mathrm{M}} \cdot \mathrm{C}_{\mathrm{W}} \\
-\mathrm{r}_{\mathrm{AA}}=-\mathrm{k}_{1} \mathrm{C}_{\mathrm{G}} \cdot \mathrm{C}_{\mathrm{AA}}+\mathrm{k}_{2} \mathrm{C}_{\mathrm{M}} \cdot \mathrm{C}_{\mathrm{W}}-\mathrm{k}_{3} \mathrm{C}_{\mathrm{M}} \cdot \mathrm{C}_{\mathrm{AA}}+\mathrm{k}_{4} \mathrm{C}_{\mathrm{D}} \cdot \mathrm{C}_{\mathrm{W}}-\mathrm{k}_{5} \mathrm{C}_{\mathrm{D}} \cdot \mathrm{C}_{\mathrm{AA}}+\mathrm{k}_{6} \mathrm{C}_{\mathrm{T}} \cdot \mathrm{C}_{\mathrm{W}} \\
-\mathrm{r}_{\mathrm{M}}=\mathrm{k}_{1} \mathrm{C}_{\mathrm{G}} \cdot \mathrm{C}_{\mathrm{AA}}-\mathrm{k}_{2} \mathrm{C}_{\mathrm{M}} \cdot \mathrm{C}_{\mathrm{W}}-\mathrm{k}_{3} \mathrm{C}_{\mathrm{M}} \cdot \mathrm{C}_{\mathrm{AA}}+\mathrm{k}_{4} \mathrm{C}_{\mathrm{D}} \cdot \mathrm{C}_{\mathrm{W}} \\
-\mathrm{r}_{\mathrm{D}}=\mathrm{k}_{3} \mathrm{C}_{\mathrm{M}} \cdot \mathrm{C}_{\mathrm{AA}}-\mathrm{k}_{4} \mathrm{C}_{\mathrm{D}} \cdot \mathrm{C}_{\mathrm{W}}-\mathrm{k}_{5} \mathrm{C}_{\mathrm{D}} \cdot \mathrm{C}_{\mathrm{AA}}+\mathrm{k}_{6} \mathrm{C}_{\mathrm{T}} \cdot \mathrm{C}_{\mathrm{W}} \\
-\mathrm{r}_{\mathrm{T}}=\mathrm{k}_{5} \mathrm{C}_{\mathrm{D}} \cdot \mathrm{C}_{\mathrm{AA}}-\mathrm{k}_{6} \mathrm{C}_{\mathrm{T}} \cdot \mathrm{C}_{\mathrm{W}} \\
-\mathrm{r}_{\mathrm{W}}=\mathrm{k}_{1} \mathrm{C}_{\mathrm{G}} \cdot \mathrm{C}_{\mathrm{AA}}-\mathrm{k}_{2} \mathrm{C}_{\mathrm{M}} \cdot \mathrm{C}_{\mathrm{W}}+\mathrm{k}_{3} \mathrm{C}_{\mathrm{M}} \cdot \mathrm{C}_{\mathrm{AA}}-\mathrm{k}_{4} \mathrm{C}_{\mathrm{D}} \cdot \mathrm{C}_{\mathrm{W}}+\mathrm{k}_{5} \mathrm{C}_{\mathrm{D}} \cdot \mathrm{C}_{\mathrm{AA}}-\mathrm{k}_{6} \mathrm{C}_{\mathrm{T}} \cdot \mathrm{C}_{\mathrm{W}}
\end{gathered}
$$

And the Arrhenius model is used,

$$
\mathrm{k}_{\mathrm{i}}=\mathrm{A}_{\mathrm{i}} \exp \left(\mathrm{E}_{\mathrm{i}} / \mathrm{RT}\right)
$$

where six rate constants appear in the three reaction (1,2 and 3). The equations (1) through (6) solved to get the reaction rate constant.

The aim of this work is to study the reaction kinetics for synthesis of triacetin from glycerol and acetic acid with sulfuric acid catalyst. This work is a continuation of previous studies that discuss influence the conversion and selectivity triacetin (Mufrodi et al., 2010). In this case selectivity is defined as the ratio of the desired product (triacetin) to unwanted products (monoacetin and diacetin).

\section{Results and Discussion}

\subsection{Effects of Ratio Catalyst to Glycerol and Temperature}

The reaction of triacetin was carried on the mol ratio of catalyst / glycerol at 1,5-3,0 \% and temperature range $100-120{ }^{\circ} \mathrm{C}$. Mole ratio of glycerol to acetic acid was 1:3. The reaction has been performed for 90 minute, but the 
equilibrium was attained after around 60 minute. Figure 2 shows effects of triacetin selectivity at difference mole ratio during the reaction. From figure 2 we may say that the mole catalyst to glycerol were increased with increase in selectivity of triacetin. But we can notice that in experiment, mole catalyst to glycerol of $3 \%$ caused the formation of the crust so this condition should be avoided.

Figure 3 shows the second reaction highest than the others reaction. It is similar with the experiment that the second reaction produce highest yield. From figure 3, we can also notice that increasing mol ratio of catalyst/glycerol from $2,5 \%$ to $3,0 \%$ does not influence triacetin selectivity significantly.

Reaction of triacetin from glycerol and acetic acid is an exothermic reactions (Atkins \& Paula, 2006), that is identified by the increase in temperature and resulting in the balance to shift the reaction towards the formation of the reactants. It will reduce the conversion of glycerol. This can be seen in Figure 4. Increasing reaction temperature will decrease the conversion of glycerol.

The opposite to the selectivity, higher reaction temperature will increased selectivity of triacetin at temperature of $100-115{ }^{\circ} \mathrm{C}$. For the temperature above $115{ }^{\circ} \mathrm{C}$, triacetin selectivity began to decrease. It is caused by the fact that at the temperature below $115{ }^{\circ} \mathrm{C}$, all reactants and products (except water) are in the liquid phase. When the temperature is higher than $118{ }^{\circ} \mathrm{C}$, some acetic acid will begin to evaporate. It will reduce selectivity of triacetin (Figure 5).

\subsection{The Study of Reaction Kinetics}

The optimal condition to study the kinetics are determined from these parameters: the mole ratio of glycerol and acetic acid is $=1 / 3$, the mole ratio of catalyst and glycerol is $2,5 \%$ at a temperatures between $100-120{ }^{\circ} \mathrm{C}$. From experimental data, they had processed with equations (1) through (6) to solve reaction rate constants. They show in Table 1.

Table 1 shows effect of temperature on reaction rate constant value at temperatures $100-120{ }^{\circ} \mathrm{C}$. The reaction rate of diacetin $\left(\mathrm{k}_{3}\right)$ is highest than the others reaction rate. This is in line with the results of experimental study that the diacetin product is highest than the others. From Table-1 we can also show that the reaction temperature was increased with increase in the reaction rate constant. According to the Arrhenius equation, the value of $\ln \mathrm{K}_{\mathrm{i}}$ is proportional to $1 / \mathrm{T}$.

In the reversible and exothermic reactions, if the temperature is raised than a reaction would be shifted towards the formation of the reactants. This condition should be anticipated in several ways so that equilibrium is still shifted to the right for formation of products. This is in line with the van't Hoff equation that raised equilibrium constant is proportional to $1 / \mathrm{T}$. In other words, the $\ln \mathrm{K}$ in reaction temperature leads to decrease (Atkins et al., 2006) the phenomena can be seen in Figure 6.

Pre-exponential factors (A) and activation energies (E) of Arrhenius constants are show in Table 2. Activation energies for $\mathrm{k}_{1}$ and $\mathrm{k}_{3}$ are smaller than the others. This indicates the formation of monoacetin immediately will turn into diacetin. This phenomenon is in line with the condition the product of diacetin is more than triacetin.

\section{Conclusion}

Synthesis triacetin from biodiesel derived waste (glycerol) and acetic acid with sulfuric acid catalyst get good results on condition of mole ratio of catalyst and glycerol $2,5 \%$, temperature of $115{ }^{\circ} \mathrm{C}$, reaction time 90 minute with a selectivity of triacetin $77.84 \%$. Selectivity triacetin increased with increase in the reaction temperature. The reaction temperature decreased when the acetic acid began to evaporate. The reaction is an exothermic reaction. So the reaction temperature increased with in shift the balance toward the formation of the reactants. It should be anticipated by taking products that keep the equilibrium leads to the formation of products.

\section{References}

Atkins, P., \& Paula, J. (2006). Atkins'Physical Chemistry, $8^{\text {th }}, 200-234$. Oxford University Press, New York.

Balaraju, M., Nikhitha, P., Jagadeeswaraiah, K. Srilatha, Prasad, P. S. S., \& Lingaiah, N. (2010). Acetylation of glycerol to synthesize bioadditives over niobic acid supported tungstophosphoric acid catalysts. Fuel Process. Technol., 91, 249-253. http://dx.doi.org/10.1016/j.fuproc.2009.10.005

Bonet J., Costa J., Sire R., Reneaume J. M., Plesu E. A., Plesu V., \& Bozga G. (2009). Revalorization of glycerol: Comestible oil from biodiesel synthesis. Food and Bioproducts Process, 87, 171-178. http://dx.doi.org/10.1016/j.fbp.2009.06.003

Ferreira, P., Fonseca, I. M., Ramos, A. M., Vital, J., \& Castanheiro, J. E. (2009). Esterification of Glycerol with Acetic Acid over Dodecamolybdophosphoric Acid Encaged in USY, Zeolite. Catal Commun, 10, $481-484$. 
http://dx.doi.org/10.1016/j.catcom.2008.10.015

Ferreira, P., Fonseca, I. M., Ramos, A.M., Vital, J., \& Castanheiro, J. E. (2011). Acetylation of glycerol over heteropolyacids supported on activated carbon. Catal Commun, 12, 573-576. http://dx.doi.org/10.1016/j.catcom.2010.11.022

Fukumura, T., Toda, T., Seki, Y., Kubo, M., Kitakawa, N. S., \& Yonemoto, T. (2009). Catalytic Synthesis of Glycerol Monoacetate Using a Continuous Expanded Bed Column Reactor Packed with Cation-Exchange Resin. Ind. Eng. Chem. Res., 48, 1816-1823. http://dx.doi.org/10.1021/ie800625g

Galan, M. I., Bonet, J., Sire, R., Reneaume, J. M., \& Plesu, A. E. (2009). From Residual to Use Oil: Revalorization of Glycerin from the Biodiesel Synthesis. Bioresour. Technol., 100, 3775-3778. http://dx.doi.org/10.1016/j.biortech.2009.01.066.

Goncalves, G. F. C., Pinto, B. P., Silva, J. C., \& Mota, C. J. A. (2008). Acetylation of Glycerol Catalyzed by Different Solid Acids. Catal. Today, 133-135, 673-677. http://dx.doi.org/10.1016/j.cattod.2007.12.037.

Hou, J., Zhang, Q., Shi, W., \& Li, Y. (1998). New Process for synthesis of Triacetin. Henan Huagon, 15(6), 18-19.

Khayoon, M. S. and Hameed, B. H. (2011). Acetylation of glycerol to biofuel additives over sulfated activated carbon catalyst. Bioresour. Technol., 102, 9229-9235, http://dx.doi.org/10.1016/j.biortech.2011.07.035

Liao X., Zhu Y., Wang S. G., \& Li Y. (2009). Producing Triacetylglycerol with Glycerol by Two Steps: Esterification and Acetylation. J. Fuel Process Tech, 90, 988-993. http://dx.doi.org/10.1016/j.fuproc.2009.03.015

Liao X., Zhu Y., Wang S. G., Chen H., \& Li Y. (2010). Theoretical Elucidation of Acetylating Glycerol with Acetic Acid and Acetic Anhydride. Appl. Catal. B, 94, 64-70. http://dx.doi.org/10.1016/j.apcatb.2009.10.021

Liu, H., Lu, Y., \& Gong, S. (2007). Study on Synthesis of Glycerol Triacetate using Acidic Fungtional Ionic Liquid as Catalyst. Hebei Gongye Keji, 24(1), 21-23.

Lu, Z., \& Ma, W. (1991). Study on Esterification reaction, Esterification of Glycerin with Acetic Acid using Ion Exchage Resin and Drying Agent as Catalysts, Gongzhou Shiyuan Xuebao. Ziran Kexueban, (2), 53-56.

Melero, J. A., Grieken, R. V., Morales, G., \& Paniagua, M. (2007). Acidic Mesoporous Silica for the Acetylation of Glycerol: Synthesis of Bioadditives to Petrol Fuel. Energy and Fuels, 21, 1782-1791. http://dx.doi.org/10.1021/ef060647q

Morrissette, R. A., \& Link, W. E. (1964). Gas-Liquid Cromatography of Polar Fatty Derivatives, 2. American Oil of Chem. Society, 41, 415-418. Minnesota. http://dx.doi.org/10.1007/BF0654872

Mufrodi, Z., Budiman, A., Rochmadi, \& Sutijan. (2010). Effects of Temperature and Catalyst upon Triacetin Production from Glycerol (by-Product Biodiesel Production) as Octane Booster, Proceedings of International Conference on Advances in Renewable Energy Technologies, Cyberjaya, Malaysia.

Reddy, P. S., Sudarsanam, P., Raju, G., \& Reddy B. M. (2010). Synthesis of bio-additives: Acetylation of glycerol over zirconia-based solid acid catalysts. Catal Commun, 11, 1224-1228. http://dx.doi.org/10.1016/j.catcom.2010.07.006

Silva, L. N., Gonçalves, V. L. C., \& Mota, C. J. A. (2010). Catalytic acetylation of glycerol with acetic anhydride. Catal Commun, 11, 1036-1039. http://dx.doi.org/10.1016/j.catcom.2010.05.007

Trevoy, L. W., \& Tegg, D. (1963). Purification of Triacetin, US Patent, 3, 108, 133.

Wu, H., Yu, B., \& Ge, S. (2007). Complex Solid Super Acid $\mathrm{SO}_{4}{ }^{2-} / \mathrm{ZrO}^{2-} \mathrm{TiO}_{2}$ used in Synthesis of Glycerol Triacetate. Huagon jinzhan, 26(7), 1041-1043.

Zang, M., \& Yuan, X. (2001). Synthesis of Glycerol Triacetate Catalized by Phosphotungstic Acid. Hecheng Hиахие, 9(5), 469-472. http://dx.doi.org/10.1002/jctb.2223 
Table 1. Effect of Temperature on Reaction Rate Constant Value

\begin{tabular}{|c|c|c|c|c|c|c|}
\hline Temperature, ${ }^{\circ} \mathrm{C}$ & $\mathrm{k}_{1}$ & $\mathrm{k}_{2}$ & $\mathrm{k}_{3}$ & $\mathrm{k}_{4}$ & $\mathrm{k}_{5}$ & $\mathrm{k}_{6}$ \\
\hline 100 & 0.02137 & 0.00647 & 2.61629 & 0.00013 & 0.00205 & 0.00074 \\
\hline 105 & 0.03148 & 0.00734 & 2.73854 & 0.00022 & 0.00347 & 0.00183 \\
\hline 110 & 0.03680 & 0.01123 & 3.02357 & 0.00034 & 0.00436 & 0.00232 \\
\hline 115 & 0.02125 & 0.01176 & 3.72790 & 0.00037 & 0.00481 & 0.00281 \\
\hline 120 & 0.02803 & 0.01286 & 4.49794 & 0.00039 & 0.00500 & 0.00243 \\
\hline
\end{tabular}

Table 2. Pre-exponential Factor and Activation Energies

\begin{tabular}{|c|c|c|}
\hline Reaction rate constant & $\mathrm{A}, \mathrm{ml} /($ mole.min) & E, cal/mole \\
\hline $\mathrm{k}_{1}$ & 0.0935 & 942.94 \\
\hline $\mathrm{k}_{2}$ & $13,629.6112$ & $10,782.09$ \\
\hline $\mathrm{k}_{3}$ & $132,986.1145$ & $8,078.70$ \\
\hline $\mathrm{k}_{4}$ & $331,041.8230$ & $15,924.92$ \\
\hline $\mathrm{k}_{5}$ & $43,477.5504$ & $12,372.84$ \\
\hline $\mathrm{k}_{6}$ & $653,436.0830$ & $15,015.33$ \\
\hline
\end{tabular}

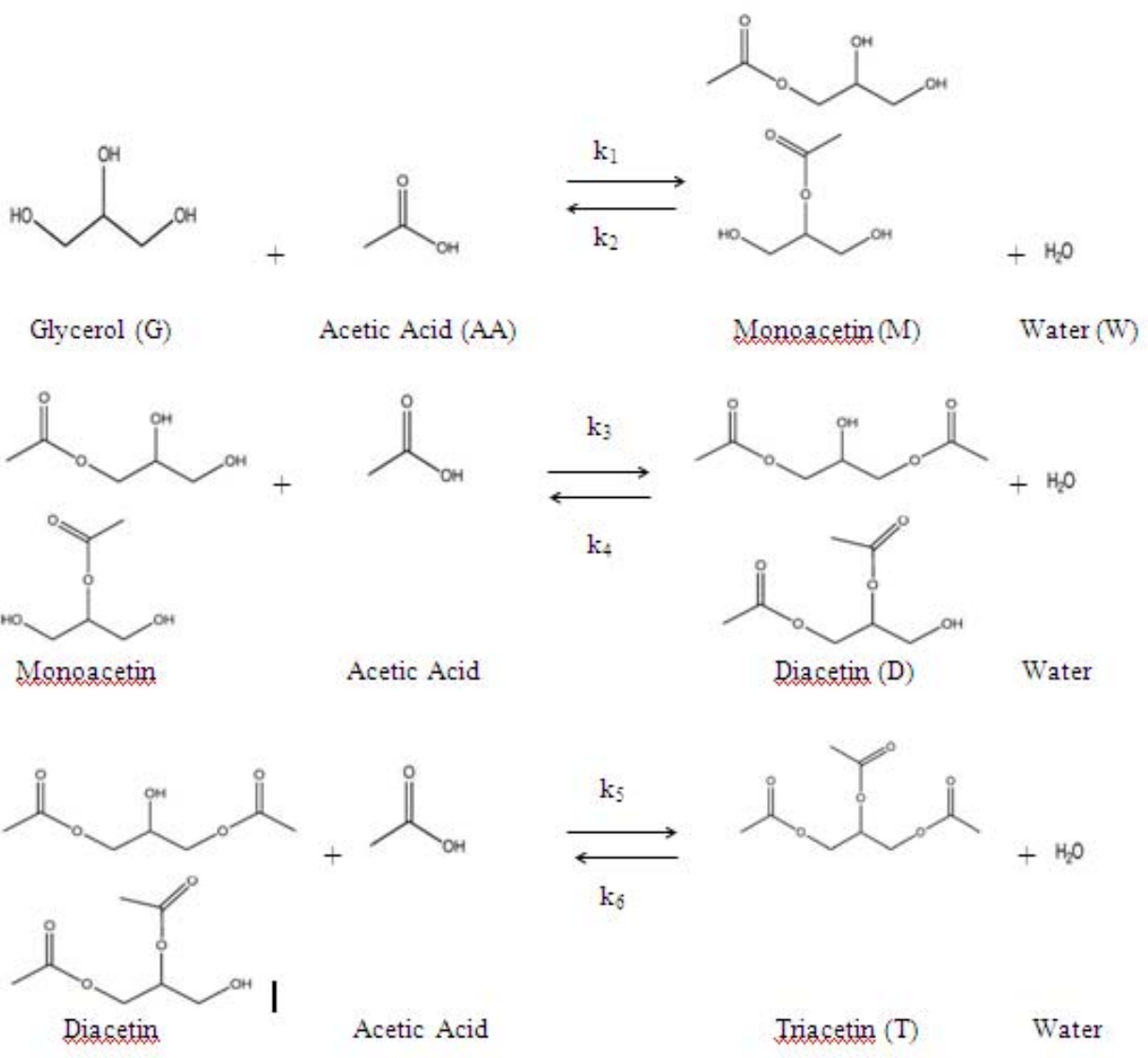

Figure 1. Acetylation of Glycerol reaction mechanism 


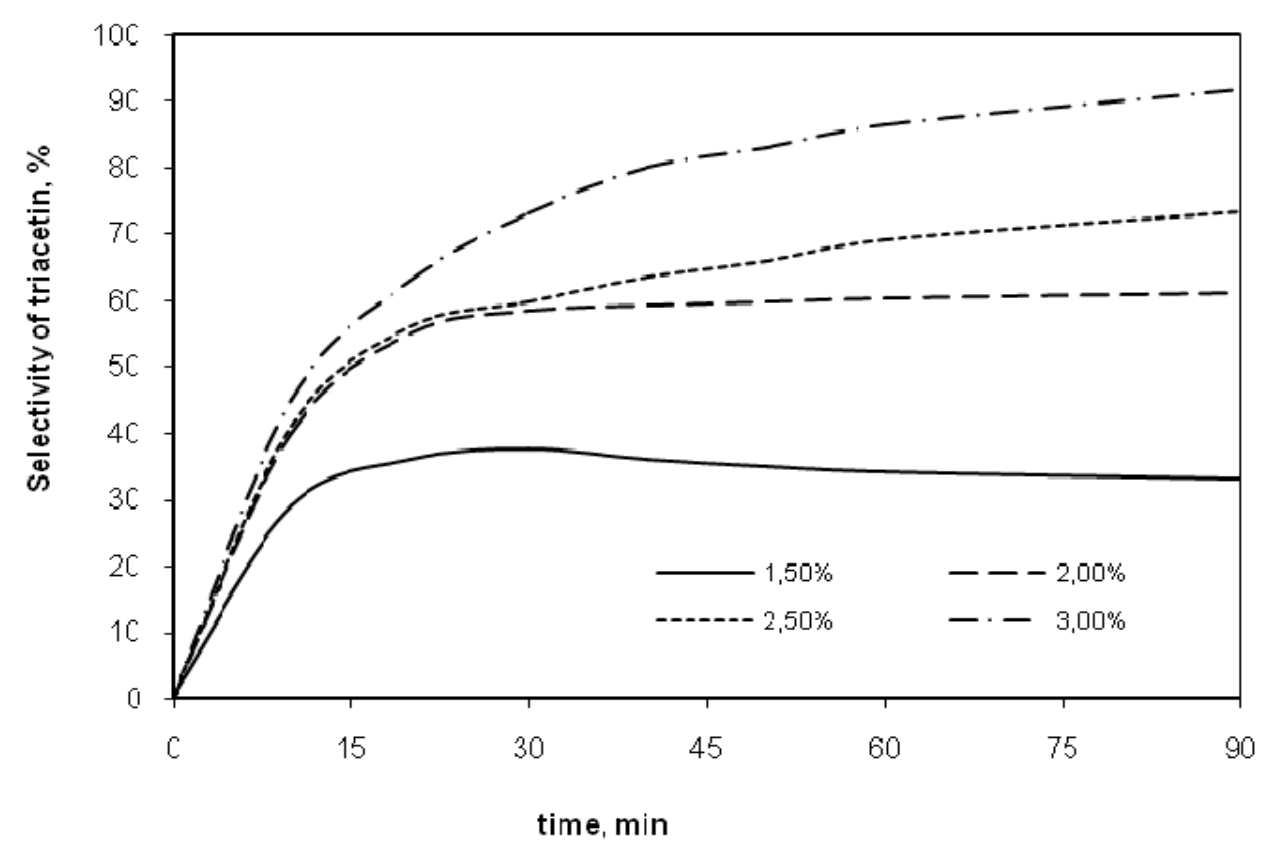

Figure 2. Effect of percents mole catalyst/glycerol to selectivity of triacetin

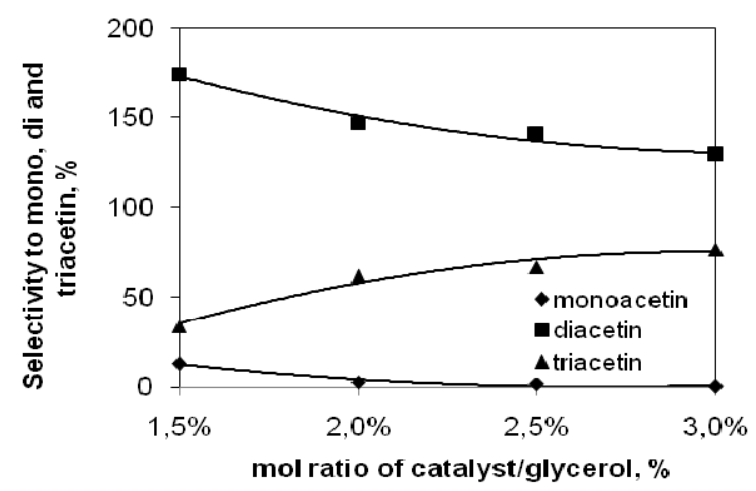

Figure 3. Selectivity to mono, di and triacetin for glycerol acetilation with acetic acid, effect of percent mol ratio of catalyst/glycerol

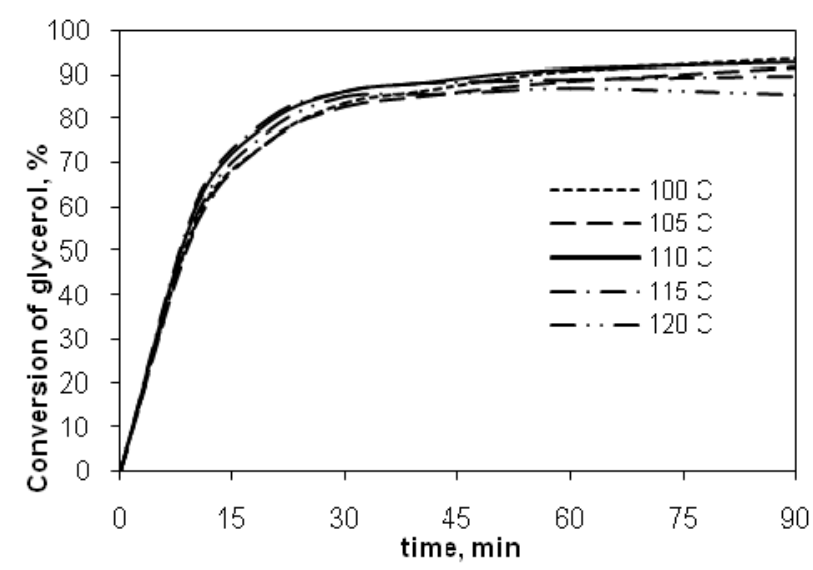

Figure 4. Effect of reaction temperatures to the percent conversion of glycerol 


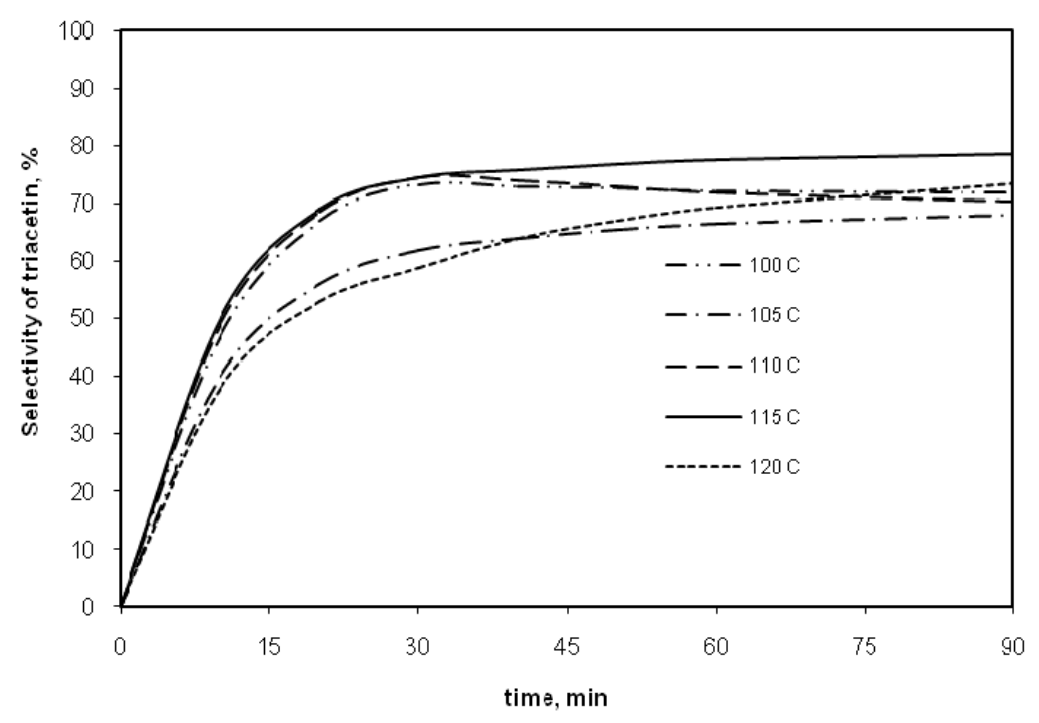

Figure 5. Effect of reaction temperatures to selectivity of triacetin

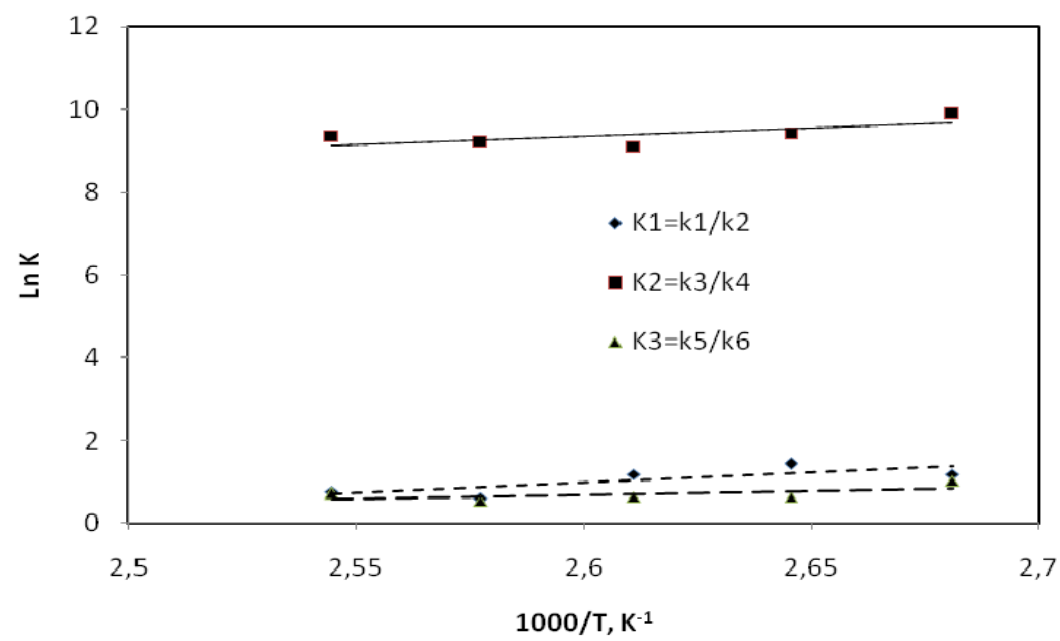

Figure 6. Relationship between $\ln \mathrm{K}$ with 1000 / T 